
Boyu ve Yaş Ağırlıklarına Bazı ALS ve ACCase Inhibitörü Herbisitlerin Etkileri

\title{
Hilmi TORUN
}

Biyolojik Mücadele Araştırma Enstitüsü Müdürlüğü, 01321-Yüreğir/Adana

https://orcid.org/0000-0001-6730-8809

凹: hilmitorun@hotmail.com

\section{ÖZET}

Bu çalışma 2013 ve 2014 yıllarında farklı etki mekanizmasına sahip olan Mesosulfuron-methyl + Iodosulfuron-methyl sodium (ALS) ve Clodinafop-propargyl (ACCase) herbisitlerinin kısır yabani yulaf (Avena sterilis L.) popülasyonlarına karşı etkisinin belirlenmesi amacıyla yapılmıştır. Osmaniye ili buğday tarlalarından toplanan kısır yabani yulafa ait popülasyonlarla kurulan sera denemelerinde uygulanan herbisitlerin bitki boyu ve yaş ağırlı̆̆a olan etkileri incelenmiştir. Osmaniye ili yoğun buğday ekimi yapılan alanlarda Mayıs ayında her $3 \mathrm{~km}$ 'de bir 50 noktada duruş yapılarak sadece 15 tarlada kısır yabani yulaf popülasyonlarına ait örneklemeler gerçekleştirilmiştir. Daha sonra buğday tarlalarından toplanan olgun kısır yabani yulaf tohumlarıyla sera denemeleri kurulmuştur. Popülasyonlarda bitki boyu ve yaş ağırlığa olan etkinin belirlenmesinde iki farklı etki mekanizmasına sahip herbisitin üç farklı $(\mathrm{N} / 2, \mathrm{~N}$ : tavsiye dozu, $2 \mathrm{~N})$ dozu uygulanmıştır. Bitki boylarına göre tavsiye dozlarında ALS inhibitöründe popülasyonların \%50'sinin, ACCase inhibitöründe ise \%27'sinin etkilendiği belirlenmiştir. Yaş ağırlıklarda ise ALS inhibitöründe \%50'sinin, ACCase inhibitöründe \%20'sinin etkilendiği saptanmıştır. Popülasyonlar üzerinde tavsiye dozu başta olmak üzere, bitki boyu ve yaş ağırlığa olan genel etkiler ALS inhibitöründe daha yüksek saptanmıştır.

\section{Araştırma Makalesi}

\section{Makale Tarihçesi}

Geliş Tarihi : 22.05.2019

Kabul Tarihi : 19.07 .2019

\section{Anahtar Kelimeler}

Avena sterilis

Clodinafop-propargyl

Mesosulfuron-methyl

iodosulfuron-methyl sodium,

Bitki boyu ve yaş ağırlık,

Buğday

\section{Determination of Effects on Weed Height and Weed Biomass of Wild Oat (Avena sterilis L.) Populations in Wheat Fields against ALS and ACCase Herbicides}

\section{ABSTRACT}

This study was determined for the effect of Mesosulfuron-methyl + Iodosulfuron-methyl sodium (ALS) and Clodinafop-propargyl (ACCase) herbicides against wild oat (Avena sterilis L.) populations in 2013 and 2014. The effects of applied herbicides on weed height and weed biomass in greenhouse experiments established with wild oat populations collected from wheat fields of Osmaniye province were investigated. In intense wheat growing areas in Osmaniye province, stands were performed in 50 points in every $3 \mathrm{~km}$ in May and sampling was performed in only 15 fields of wild oat populations. Then, greenhouse tests were established with mature wild oat seeds collected from wheat fields. Three different (N/2, N: recommended dose, $2 \mathrm{~N}$ ) dose of herbicide with two different action mechanism were applied to determine the effect on height and biomass of weed populations. Population of weed height were evaluated that $50 \%$ of ALS inhibitor and $27 \%$ of ACCase inhibitor were affected at recommended doses. It was also found that 50\% of ALS inhibitor and $20 \%$ of ACCase inhibitor had an effect on weed biomass. General effects on weed height and weed biomass, especially the recommended dose on populations were higher in ALS inhibitor.

\section{Research Article}

$\begin{array}{ll}\text { Article History } & \\ \text { Received } & : 22.05 .2019 \\ \text { Accepted } & : 19.07 .2019\end{array}$

Keywords
Avena sterilis,
Clodinafop-propargyl,
mesosulfuron-methyl
iodosulfuron-methyl sodium,
Weed height and weed biomass,
Wheat

To Cite : Torun H 2019. Buğday Alanlarında Sorun Olan Kısır Yabani Yulaf (Avena sterilis L.) Popülasyonlarının Bitki Boyu ve Yaş Ağırlıklarına Bazı ALS ve ACCase Inhibitörü Herbisitlerin Etkileri. KSÜ Tarım ve Doğa Derg 23 (2): $357-365$. DOI: $10.18016 /$ ksutarimdoga.vi.568866. 


\section{GİRİŞ}

Dünyada insan beslenmesi açısından stratejik ve önemli bir yere sahip olan tahıllarda yabancı otlarla mücadele edilmemesi durumunda yabancı otlar yoğun popülasyonlar oluşturarak kalite ve kantiteyi düşürür, verim kaybina sebep olurlar.

Tahıl alanlarında sorun olan Poaceae familyasına ait kısır yabani yulaf türleri (Avena spp.) buğdayın önemli yabancı ot türlerindendir (Kadığlu ve ark., 1990; Torner ve ark., 1991; Kadıŏlu ve ark., 1993). Bu türler, buğdayın ışık, su ve besinine ortak olup, gelişimini etkileyerek rekabet güçlerini yükseltirler (Carlson ve Hill, 1985). Mücadele edilmediği takdirde yabani yulaf türlerinin buğdaya oranla hızlı gelişmesi buğdaydaki veriminin azalmasına neden olmaktadır. $\mathrm{Bu}$ nedenle bu türlerle mücadelede üreticiler kısa vadede sonuç almak için kimyasal mücadeleye yönelmiştir. Kolay uygulanması, kısa sürede etki göstermesi ve maliyetinin az olması nedeniyle üretici tarafindan tercih edilen kimyasal mücadele buğdayda yabancı ot kontrolünde günümüzde en çok kullanılan yöntemdir. Ancak üretici tarafindan doğru dozda ve yabancı ot gelişim döneminde uygulanmamasıyla birlikte, kimyasal kullanımındaki artış yabancı ot popülasyonları üzerinde herbisit etkinliğinin azalmasına sebep olmuş ve kullanılan herbisitlerin bu türleri etkilemediği görülmüştür (Legere ve ark., 2000; Valverde, 2007). Ülkemizde buğdayda kimyasal mücadelede en çok kullanılan herbisitler ACCase (Acetyl-CoA carboxylase) ve ALS (Acetolactate synthase) etki mekanizmasına sahip herbisitlerdir ve aşırı kullanımı Türkiye'deki ömrünü de kısaltmıştır. Çukurova Bölgesi'nde kullanılan ACCase ve ALS inhibitörü herbisitlerin bazı yabancı ot türlerini etkilemediği ve buğday tarlalarında zamanla çoğalarak sorunlara neden olduğu bildirilmiştir (Yücel, 2004; Avc1, 2009; Ayata, 2014; Gürbüz, 2016; Torun, 2017).

Dünya genelinde yapılan çalışmalarda yabancı otlarla kimyasal mücadelede herbisit uygulamalarının yabancı otlar üzerindeki etkilerinin belirlenmesinde bitkilerin, kök uzunluğu, tohum sayısı, yaprak fotosentez hızı, kuru ağırlığı ve yaş ağırlığı gibi parametreler baz alınarak incelenmiştir. Benzer şekilde Beckie ve Kirkland (2003) ACCase inhibitörü herbisit uygulamalarının Avena fatua popülasyonu üzerindeki etkileri belirlemek amacıyla popülasyon yoğunluğuna, tohum oluşturulmasina ve topraktaki tohum rezervlerinin canlılığına olan parametreleri incelemişlerdir. Batı Kanada'da Heap ve ark. (1993) dört tarlada Avena fatua popülasyonunda beş farklı ACCase inhibitörü (Diclofop-methyl, Fenoxaprop-Pethyl, Quizalofop-ethyl, Sethoxydim, Tralkoxydim) herbisitleri denemiş ve sadece yarıya yakın popülasyonların çok daha yüksek dozlarda öldügünü belirlemiştir. Ayrıca, yüksek dozda kök kuru ağırlığının \%27'sinde azalışların olabileceğini bildirmiştir. Amerika'da Seefeldt ve ark. (1994) Avena fatua popülasyonu örneklerinde ACCase inhibitörü Diclofop etkili maddesine karşı popülasyonların ışık kullanımının, bitki boyunun, kuru ağırlığının, yaprak yüzeyinin, kardeşlenme zamanının ve çiçeklenme sürelerinin birbirinden farklı olduğunu ortaya koymuştur.

Bu çalışmada 2013 ve 2014 yıllarında, ülkemizde buğdayın en önemli yabancı otlarından biri olan kısır yabani yulaf (Avena sterilis L.)'ta iki farklı etki mekanizmasina sahip Mesosulfuron-methyl + Iodosulfuron-methyl sodium ile Clodinafoppropargyl'in kısır yabani yulaf popülasyonları üzerindeki etkisi araştırılmıştır. Bu sayede Osmaniye ilinde örnekleme yapılan bazı kısır yabani yulaf popülasyonlarının sera denemeleri sonucunda bitki boyu gelişimine ve yaş ağırlıklarına karşı gösterdiği değişimler belirlenmiş ve bu herbisitlerin farklı uygulama dozlarındaki etkileri araştırılmıştır.

\section{MATERYAL ve METOT}

Çalışmanın ana materyalini, Osmaniye ili [Kadirli (K), Sumbas (S), Merkez (M), Düziçi (D), Toprakkale (T) ve Hasanbeyli (H)] ilçeleri buğday tarlalarından toplanan olgun kısır yabani yulaf (Avena sterilis L.) tohumları, $20 \mathrm{ml} /$ da uygulama dozunda kullanılan Clodinafoppropargyl (240 g l-1) etkili maddeli ACCase inhibitörü herbisit, $30 \mathrm{~g} / \mathrm{da}+100 \mathrm{ml}$ (yayıcı-yapıştırıcı) uygulama dozunda kullanılan Mesosulfuron-methyl + Iodosulfuron-methyl-sodium + Mefenpeyr-diethyl (Yayıcı-Yapıştırıcı) $(\% 3+\% 0.6)$ etkili maddeli ALS inhibitörü herbisit, denemelerde 3 atm basınçla çalışan şarjlı sırt pülverizatörü (Matabi), sera denemelerinde kullanılan standart fide viyolleri ve yabancı ot yaş ağırlık tartımı esnasında kullanılan kese kağıtları oluşturmuştur.

Osmaniye ilinde yoğun buğday ekilen alanlarda her 3 km'de bir rastlantısal olarak, duruş yapılan noktada buğday tarlasına girilerek 1 dekarlık alan içerisinde örnekleme yapılmıştır. Toplam olarak 2013 yılında 50 buğday tarlasına girilmiş ve sadece olgun tohuma sahip 15 tarladan kısır yabani yulaf popülasyonlarına ait örneklemeler yapılmıştır (Yücel, 2004; Ayata, 2014). İki yıl üst üste Mayıs ayı itibariyle aynı tarlalara gidilmiştir. Tarlalardan toplanan olgun tohumlar daha sonra laboratuvarda kavuzlarından ayrılmıştır. Kavuzları ayrılan tohumlar bir ay kadar $+4^{\circ} \mathrm{C}$ buzdolabında bekletilerek dormansinin kırılması sağlanmıştır.

Sera çalışmaları, Çukurova Üniversitesi Bitki Koruma Bölümüne ait seralarda yürütülmüştür. Çalışma tesadüf parselleri deneme desenine göre dört tekerrürlü ve iki kez kurulmuştur. Çalışmada kullanılan materyali oluşturan toprak daha önce hiç herbisit kullanılmamış yerden temin edilmiş ve 
viyollere konulan toprak materyali 1:1:1 oranında kum: çiftlik gübresi: toprak karışımından meydana gelmiştir. Kullanılan her viyolün bir çukur ebatı $5 \times 5$ $\mathrm{cm}$ olup, hazırlanmış olan toprak karışımı eşit miktarda olacak şekilde viyol çukurlarına dağıtılmıştır. Ardından tohumlar $2 \mathrm{~cm}$ derinliğe konduktan sonra doldurulmuştur (Yücel, 2004; Ayata, 2014; Gürbüz, 2016; Torun, 2017). Her çukura 3 adet kısır yabani yulaf tohumu ekilmiş ve 2-4 yapraklı dönemde ise en iyi gelişen bir adet kısır yabani yulaf bırakılarak herbisit uygulaması gerçekleştirilmiştir. Seçilen herbisitler yelpaze tipi meme kullanılarak uygulanmıştır. Örnekleme yapılan tarlalara ait popülasyonlardan elde edilen tohumlardan fideler yetiştirilerek, herbisitlerin üç farklı dozu $(\mathrm{N} / 2, \mathrm{~N}$ : tavsiye dozu, $2 \mathrm{~N}$ ) uygulanmıştır.

Herbisitlerin uygulama öncesi bitki boyları ölçülerek birinci sayım, uygulama sonrasındaki 28. günde ikinci sayım yapılarak bitki boyları kaydedilmiştir. Herbisitlerin etkisini tam olarak göstermiş olduğu 28. gün sonunda bitkiler toprak yüzeyinden hasat edilmiştir (Uygur ve ark., 1984). Daha sonra bitki materyalleri kese kağıtları içerisine koyulmuş ve laboratuvarda yaş ağırlıkları alınmıştır. Bir aylık bir yetişme döneminden sonra herbisitlerin farklı uygulama dozları uygulanarak popülasyonlar içerisinde dozlar arasında kıyaslamalar yapılmıştır.

$\mathrm{Bu}$ sayede bitki boyu ve yaş ağırlık belirlenerek, kullanılan farklı etki mekanizmalarına sahip herbisitlerin durumu ortaya çıkarılmış, böylelikle hangi etki mekanizmasının aynı popülasyon içerisinde daha etkili olduğu saptanmıştır. Dozlara göre elde edilen bitki boyu ve yaş ağırlık sonuçlarına SPSS istatistik programında (ANOVA) analiz yapılmış (Anonim, 2009), popülasyonlar için elde edilen ortalama değerlere Duncan çoklu karşılaştırma testi uygulanmıştır. Ayrıca popülasyonlar arasında tavsiye dozu hesaplanarak popülasyonların Mesosulfuronmethyl + Iodosulfuron-methyl sodium ve Clodinafoppropargyl herbisitlerine karşı gösterdiği reaksiyon ortaya çıkarılmıştır (Abbott, 1925).

\section{BULGULAR ve TARTIŞMA}

Osmaniye ilinde 2013 yılında yapılan survey sonrası 15 farklı buğday tarlasindan toplanan kısır yabani yulaf popülasyonlarına ait örneklerle sera denemeleri kurulmuştur. Ardından 2014 yılında aynı tarlalarda örneklemeler gerçekleştirilmiştir. Osmaniye'de Toprakkale'den bir adet, Hasanbeyli'den üç adet, Kadirli'den üç adet, Merkez'den iki adet, Düziçi'nden üç adet ve Sumbas'dan üç adet popülasyon denemelerde kullanılmıştır. Toplam 15 kısır yabani yulaf popülasyonu üzerinde iki farklı etki mekanizmasının bitki boy ve yaş ağırlık üzerindeki etkileri saptanmıştır (Çizelge 1, 2 ve 3). Osmaniye'de buğday tarlalarından getirilen kısır yabani yulaf popülasyonlarına ait tohumlar serada yetiştirilerek
Mesosulfuron-methyl + Iodosulfuron-methyl sodium ve Clodinafop-propargyl herbisitleri uygulanmıştır.

Hasat sonrası yaş ağırlıklar kendi içinde incelendiğinde Mesosulfuron-methyl + Iodosulfuronmethyl sodium'a 15 popülasyon içerisinde $\% 50$ 'sinin (yedi popülasyon) tavsiye dozunda istatistiki olarak etkilendiği belirlenmiştir. Tavsiye dozunda etkili olan popülasyonların yaş ağırlıklarının $0.53-0.64 \mathrm{~g}$ arasında değiştiği, kontrol popülasyonlarının 1.01$2.66 \mathrm{~g}$ arasında olduğu saptanmıştır. Bütün popülasyonlar içerisinde $\mathrm{K} 9, \quad \mathrm{~K} 7 \quad$ ve $\mathrm{D} 6$ populasyonlarının sadece iki katı dozda \%20'sinin etkilendiği kaydedilmiştir. Popülasyonların \%25'inde (H5, D3, S7, S3) yaş ağırlıkların tavsiye dozu ile iki katı doz aralığında etki ettiği görülmüştür. Tavsiye dozu ile iki katı doz aralığında etki saptanan yaş ağırlıkların 0.52-0.79 g arasında olduğu belirlenmiştir. M3 popülasyonunun ise tavsiye dozunun yarısından itibaren istatistiki olarak etkilendiği belirlenmiştir (Çizelge 1).

Clodinafop-propargyl'in \%20'sinin sadece üç popülasyonda (T5, H2, D6) tavsiye dozunda 0.80-0.86 g arasında etkilendiği gözlenmiştir. D3 populasyonunun sadece iki katı uygulama dozunda ve K9, M11, D1 ile S7 popülasyonun \%27'sinin tavsiye dozu ile iki katı doz aralığında etkilendiği istatistiki anlamda ortaya çıkarılmıştır. Clodinafop-propargyl herbisitinin $\mathrm{H} 5, \mathrm{H} 4, \mathrm{~K} 7, \mathrm{~K} 6, \mathrm{M} 3$, S5 ve S3 popülasyonlarında tavsiye edilen dozun yarısından itibaren etkili olduğu fakat gerek tavsiye dozu yaş ağırlığının, gerekse iki katı tavsiye dozu yaş ağırlığının istatistiki anlamda ve yaş ağırlık değişimi anlamında bu popülasyonlarda kendi içerisinde birbirine yakın oluşu uygulanan herbisitin popülasyon içerisinde etkisiz olabileceğini kısaca etkinin görülmeyebileceğini düşündürmüştür. Sadece iki katı dozda etki görülen D3 popülasyonun yaş ağırlığının benzer şekilde minimum $0.82 \mathrm{~g}$ olduğu kaydedilmiştir. Kontrolün ise maksimum $1.65 \mathrm{~g}$ yaş ağırlığa sahip olduğu Çizelge 1'de gözlenmiştir. Kadıoğlu ve ark. (1990) buğday ekim alanlarında kullanılan Dichlofopmethyl etkili maddeli herbisitin kısır yabani yulafin mücadelesinde 2-4 yapraklı dönemde tek başına yeterli olduğunu, ancak ilerleyen gelişim döneminde bitki ağırlığının azaltılması için başka etki mekanizmasina sahip herbisitlerin mutlaka kombine edilerek kullanılması gerektiğini bildirmiştir. Benzer şekilde Avustralya'da Mansooji ve ark. (1992) ACCase inhibitörleriyle kurdukları denemelerde Avena türlerine ait topladıkları popülasyonların sadece \%67'sinin herbisitler tarafindan etkilendiğini ve bitki ağırlıklarında azalmaların olabileceğini belirlemiştir.

Sera denemelerinde uygulamadan sonra seçilen bütün dozlarda Mesosulfuron-methyl + Iodosulfuron-methyl sodium'un, Clodinafop-propargyl'e göre yaş ağırlığı daha fazla azalttığı gözlenmiştir (Çizelge 1). Ancak Heap ve Knight (1986) ACCase inhibitörü olan 
Diclofop-methyl'i Lolium rigidum popülasyonlarına uygulamış, bu popülasyonlara aynı etki mekanizmasına sahip Fluazifop-butyl ve Oxyfluorfen aktif maddelerini uygulayarak kullanılan tüm aktif maddelerin artık popülasyonlar üzerinde etkisi olmadığını bildirmiştir.

Çizelge 1. 2013 ve 2014 yıllarında Osmaniye ili örnekleme yapılan ilçelerde kısır yabani yulaf popülasyonlarıyla kurulan sera denemeleri sonucu Mesosulfuron-methyl + Iodosulfuron-methyl sodium (ALS) ve Clodinafop-propargyl (ACCase) herbisitlerinin bitki yaş ağırlığ

Table 1. The effect of Mesosulfuron-methyl + Iodosulfuron-methyl sodium (ALS) and Clodinafop-propargyl (ACCase) herbicides on weed biomass (g) averages of screenhouse tests with wild oat populations in the sampling districts of Osmaniye province in 2013 and 2014

\begin{tabular}{|c|c|c|c|c|c|c|c|c|}
\hline \multirow[b]{2}{*}{$\begin{array}{l}\text { Yaş Ağırlık (g) } \\
\text { Weed biomass }(g)\end{array}$} & \multicolumn{4}{|c|}{$\begin{array}{c}\text { Mesosulfuron-methyl + } \\
\text { Iodosulfuron-methyl sodium (ALS) }\end{array}$} & \multicolumn{4}{|c|}{ Clodinafop-propargyl (ACCase) } \\
\hline & $\begin{array}{l}\text { Kontrol } \\
\text { Control }\end{array}$ & $\mathrm{N} / 2$ & $\begin{array}{c}\text { N (Tavsiye dozu) } \\
\text { Recommended } \\
\text { dose }\end{array}$ & $2 \mathrm{~N}$ & $\begin{array}{l}\text { Kontrol } \\
\text { Control }\end{array}$ & $\mathrm{N} / 2$ & $\begin{array}{c}\text { N (Tavsiye dozu) } \\
\text { Recommended } \\
\text { dose }\end{array}$ & $2 \mathrm{~N}$ \\
\hline Toprakkale 5(T5) & $2.66 \mathrm{c}$ & $\begin{array}{c}1.01 \mathrm{~b} \\
\mathrm{CD}\end{array}$ & $\begin{array}{c}0.61 \mathrm{a} \\
\mathrm{AB}\end{array}$ & $\begin{array}{c}0.59 \mathrm{a} \\
\mathrm{BCD}\end{array}$ & $1.35 \mathrm{~b}$ & $\begin{array}{c}1.27 \mathrm{~b} \\
\mathrm{FG}\end{array}$ & $\begin{array}{c}0.86 \mathrm{a} \\
\mathrm{A}\end{array}$ & $\begin{array}{c}0.95 \mathrm{a} \\
\mathrm{B}\end{array}$ \\
\hline Hasanbeyli 5(H5) & $2.11 \mathrm{c}$ & $\begin{array}{l}1.02 \mathrm{~b} \\
\mathrm{CD}\end{array}$ & $\begin{array}{c}0.52 \mathrm{a} \\
\mathrm{A}\end{array}$ & $\begin{array}{l}0.67 \mathrm{ab} \\
\mathrm{DE}\end{array}$ & $1.28 \mathrm{~b}$ & $\begin{array}{l}1.00 \mathrm{a} \\
\mathrm{BC}\end{array}$ & $\begin{array}{l}1.24 \mathrm{~b} \\
\mathrm{BC}\end{array}$ & $\begin{array}{c}0.99 \mathrm{a} \\
\mathrm{B}\end{array}$ \\
\hline Hasanbeyli 4(H4) & $1.30 \mathrm{c}$ & $\begin{array}{l}1.00 \mathrm{~b} \\
\mathrm{CD}\end{array}$ & $\begin{array}{c}0.62 \mathrm{a} \\
\mathrm{AB}\end{array}$ & $\begin{array}{l}0.65 \mathrm{a} \\
\mathrm{DE}\end{array}$ & $1.16 \mathrm{ab}$ & $\begin{array}{c}0.93 \mathrm{a} \\
\mathrm{AB}\end{array}$ & $\begin{array}{c}0.87 \mathrm{a} \\
\mathrm{A}\end{array}$ & $\begin{array}{c}0.82 \mathrm{a} \\
\mathrm{AB}\end{array}$ \\
\hline Hasanbeyli 2(H2) & $1.80 \mathrm{c}$ & $\begin{array}{c}1.02 \mathrm{~b} \\
\mathrm{D}\end{array}$ & $\begin{array}{c}0.64 \mathrm{a} \\
\mathrm{AB}\end{array}$ & $\begin{array}{l}0.78 \mathrm{a} \\
\mathrm{FG}\end{array}$ & $1.64 \mathrm{c}$ & $\begin{array}{l}1.19 \mathrm{~b} \\
\mathrm{EFG}\end{array}$ & $\begin{array}{c}0.83 \mathrm{a} \\
\mathrm{A}\end{array}$ & $\begin{array}{c}0.81 \mathrm{a} \\
\mathrm{AB}\end{array}$ \\
\hline Kadirli 9(K9) & $1.01 \mathrm{c}$ & $\begin{array}{c}0.66 \mathrm{~b} \\
\mathrm{~A}\end{array}$ & $\begin{array}{c}0.63 \mathrm{~b} \\
\mathrm{AB}\end{array}$ & $\begin{array}{c}0.49 \mathrm{a} \\
\mathrm{A}\end{array}$ & $1.50 \mathrm{~d}$ & $\begin{array}{c}0.81 \mathrm{~b} \\
\mathrm{~A}\end{array}$ & $\begin{array}{c}0.73 \mathrm{a} \\
\mathrm{A}\end{array}$ & $\begin{array}{c}0.85 \mathrm{c} \\
\mathrm{AB}\end{array}$ \\
\hline Kadirli 7(K7) & $1.89 \mathrm{c}$ & $\begin{array}{l}0.99 \mathrm{~b} \\
\mathrm{CD}\end{array}$ & $\begin{array}{c}0.66 \mathrm{ab} \\
\mathrm{AB}\end{array}$ & $\begin{array}{c}0.52 \mathrm{a} \\
\mathrm{AB}\end{array}$ & $1.62 \mathrm{~b}$ & $\begin{array}{l}1.04 \mathrm{a} \\
\mathrm{BCD}\end{array}$ & $\begin{array}{c}1.34 \mathrm{a} \\
\mathrm{C}\end{array}$ & $\begin{array}{c}1.24 \mathrm{a} \\
\mathrm{C}\end{array}$ \\
\hline Kadirli 6(K6) & $1.89 \mathrm{c}$ & $\begin{array}{l}1.05 \mathrm{~b} \\
\mathrm{BCD}\end{array}$ & $\begin{array}{c}0.53 \mathrm{a} \\
\mathrm{A}\end{array}$ & $\begin{array}{c}0.51 \mathrm{a} \\
\mathrm{AB}\end{array}$ & $1.65 \mathrm{~b}$ & $\begin{array}{c}0.97 \mathrm{a} \\
\mathrm{B}\end{array}$ & $\begin{array}{c}0.95 \mathrm{a} \\
\mathrm{A}\end{array}$ & $\begin{array}{c}1.42 \mathrm{~b} \\
\mathrm{D}\end{array}$ \\
\hline Merkez 11(M11) & $1.62 \mathrm{c}$ & $\begin{array}{c}1.01 \mathrm{~b} \\
\mathrm{CD}\end{array}$ & $\begin{array}{c}0.62 \mathrm{a} \\
\mathrm{AB}\end{array}$ & $\begin{array}{c}0.60 \mathrm{a} \\
\mathrm{CD}\end{array}$ & $1.16 \mathrm{c}$ & $\begin{array}{l}1.12 \mathrm{c} \\
\mathrm{CDE}\end{array}$ & $\begin{array}{c}0.82 \mathrm{a} \\
\mathrm{A}\end{array}$ & $\begin{array}{c}0.95 \mathrm{~b} \\
\mathrm{~B}\end{array}$ \\
\hline Merkez 3(M3) & $1.69 \mathrm{~b}$ & $\begin{array}{c}1.00 \mathrm{a} \\
\mathrm{CD}\end{array}$ & $\begin{array}{c}0.63 \mathrm{a} \\
\mathrm{AB}\end{array}$ & $\begin{array}{c}0.62 \mathrm{a} \\
\mathrm{DE}\end{array}$ & $1.54 \mathrm{~b}$ & $\begin{array}{c}1.00 \mathrm{a} \\
\mathrm{BC}\end{array}$ & $\begin{array}{c}0.82 \mathrm{a} \\
\mathrm{A}\end{array}$ & $\begin{array}{c}0.88 \mathrm{a} \\
\mathrm{AB}\end{array}$ \\
\hline Düziçi 6(D6) & $1.12 \mathrm{~d}$ & $\begin{array}{c}0.89 \mathrm{c} \\
\mathrm{BC}\end{array}$ & $\begin{array}{c}0.63 \mathrm{~b} \\
\mathrm{AB}\end{array}$ & $\begin{array}{c}0.53 \mathrm{a} \\
\mathrm{ABC}\end{array}$ & $1.40 \mathrm{c}$ & $\begin{array}{c}0.95 \mathrm{~b} \\
\mathrm{~B} \\
\end{array}$ & $\begin{array}{c}0.80 \mathrm{a} \\
\mathrm{A}\end{array}$ & $\begin{array}{c}0.74 \mathrm{a} \\
\mathrm{A} \\
\end{array}$ \\
\hline Düziçi 3(D3) & $1.06 \mathrm{~d}$ & $\begin{array}{c}0.86 \mathrm{c} \\
\mathrm{B}\end{array}$ & $\begin{array}{c}0.61 \mathrm{a} \\
\mathrm{AB}\end{array}$ & $\begin{array}{c}0.70 \mathrm{~b} \\
\mathrm{EF}\end{array}$ & $1.33 \mathrm{c}$ & $\begin{array}{c}0.98 \mathrm{~b} \\
\mathrm{BC}\end{array}$ & $\begin{array}{c}1.00 \mathrm{~b} \\
\mathrm{AB}\end{array}$ & $\begin{array}{c}0.82 \mathrm{a} \\
\mathrm{AB}\end{array}$ \\
\hline Düziçi 1(D1) & $1.29 \mathrm{c}$ & $\begin{array}{c}0.95 \mathrm{~b} \\
\mathrm{BCD}\end{array}$ & $\begin{array}{c}0.61 \mathrm{a} \\
\mathrm{AB}\end{array}$ & $\begin{array}{c}0.64 \mathrm{a} \\
\mathrm{DE}\end{array}$ & $1.38 \mathrm{c}$ & $\begin{array}{c}1.17 \mathrm{bc} \\
\mathrm{DEF}\end{array}$ & $\begin{array}{c}0.83 \mathrm{a} \\
\mathrm{A}\end{array}$ & $\begin{array}{c}0.91 \mathrm{ab} \\
\mathrm{AB}\end{array}$ \\
\hline Sumbas 7(S7) & $2.20 \mathrm{c}$ & $\begin{array}{c}1.28 \mathrm{~b} \\
\mathrm{E}\end{array}$ & $\begin{array}{c}0.64 \mathrm{a} \\
\mathrm{AB}\end{array}$ & $\begin{array}{c}0.77 \mathrm{ab} \\
\mathrm{FG}\end{array}$ & $1.53 \mathrm{~b}$ & $\begin{array}{c}1.23 \mathrm{ab} \\
\mathrm{EFG}\end{array}$ & $\begin{array}{c}0.92 \mathrm{a} \\
\mathrm{A}\end{array}$ & $\begin{array}{c}1.22 \mathrm{ab} \\
\mathrm{C}\end{array}$ \\
\hline Sumbas 5(S5) & $1.12 \mathrm{~b}$ & $\begin{array}{c}1.30 \mathrm{c} \\
\mathrm{E}\end{array}$ & $\begin{array}{c}0.64 \mathrm{a} \\
\mathrm{AB}\end{array}$ & $\begin{array}{c}0.77 \mathrm{a} \\
\text { FG }\end{array}$ & $1.52 \mathrm{~b}$ & $\begin{array}{c}1.32 \mathrm{a} \\
\mathrm{G}\end{array}$ & $\begin{array}{c}1.28 \mathrm{a} \\
\mathrm{BC}\end{array}$ & $\begin{array}{c}1.43 \mathrm{ab} \\
\mathrm{D}\end{array}$ \\
\hline Sumbas 3(S3) & $1.15 \mathrm{~d}$ & $\begin{array}{c}1.01 \mathrm{c} \\
\mathrm{CD}\end{array}$ & $\begin{array}{c}0.70 \mathrm{a} \\
\mathrm{B} \\
\end{array}$ & $\begin{array}{c}0.79 a b \\
G\end{array}$ & $1.51 \mathrm{~b}$ & $\begin{array}{c}1.29 \mathrm{a} \\
\mathrm{FG}\end{array}$ & $\begin{array}{c}1.27 \mathrm{a} \\
\mathrm{BC}\end{array}$ & $\begin{array}{c}1.43 \mathrm{ab} \\
\mathrm{D}\end{array}$ \\
\hline
\end{tabular}

*Aynı satırda farklı küçük harflerle ve aynı sütunda farklı büyük harflerle gösterilen ortalamalar Duncan Çoklu Karşılaştırma Testine göre $\mathrm{P}<0.05$ önem seviyesinde birbirinden farklıdır.

Popülasyonların yaş ağırlıkları incelendiğinde Mesosulfuron-methyl + Iodosulfuron-methyl sodium'un tavsiye dozunda Clodinafop-propargyl'e göre daha fazla popülasyonda etki görülmüştür. Hatta Clodinafop-propargyl'in bazı popülasyonlarda (H5, H4, $\mathrm{K} 7, \mathrm{~K} 6, \mathrm{M} 3$, S5 ve S3) yaş ağırlığa olan etkilerinin neredeyse tüm uygulama dozlarında aynı olduğu kaydedilmiştir. Mesosulfuron-methyl + Iodosulfuronmethyl sodium herbisitinin tavsiye dozunda yaş ağırlığa olan etkisinin (0,53-0.64 g), Clodinafoppropargyl herbisitine (0.80-0.86 g) göre daha yüksek olduğu saptanmıştır. Yaş ağırlığa göre Mesosulfuronmethyl + Iodosulfuron-methyl sodium herbisitinin tavsiye dozu ile iki katı doz aralığında etki görülen popülasyonlarda (0.52-0.79 g) da benzer şekilde Clodinafop-propargyl herbisitine göre (0.74-0.95 g) daha fazla etki gözlenmiştir (Çizelge 1). Avustralya'da Preston ve Powles (2002) yaptıkları çalışmalarda tarlalarda uzun süre kullanılan ALS inhibitörü 
herbisitleri Lolium rigidum popülasyonları üzerine uygulayarak bitki içerisindeki biyokimyasal döngüleri takip etmiştir. $\mathrm{Bu}$ popülasyonlara uygulanan ALS inhibitörü herbisitlerinin etkisinin çok kısa bir sürede kaybolabileceğini ve zamanla etkisini yitiribileceğini bildirmiştir. Popülasyonlar içerisinde tavsiye dozunda T5 ve H2'nin, tavsiye dozu ile iki katı doz aralığında S7'nin her iki inhibitor tarafından etkilendiği saptanmıştır. Popülasyonlar arasında Mesosulfuronmethyl + Iodosulfuron-methyl sodium herbisitinin tavsiye dozunun yarısında K9 popülasyonunu, tavsiye dozunda $\mathrm{H} 5$ ve $\mathrm{K} 6$ popülasyonları ve sadece iki katında gene K9 popülasyonunda en etkili olduğu istatistiki olarak bulunmuştur. Clodinafop-propargyl tavsiye dozunun yarısinda K9, tavsiye dozunda H5, K7, K3, D3 ve S5 popülasyonları hariç diğer tüm popülasyonlarda ve tavsiye dozunun iki katı uygulamasinda istatistiki anlamda en fazla etki D6 popülasyonda belirlenmiştir. Ayrıca popülasyonlar arasında her iki herbisitte tavsiye dozunun yarısında K9'da, tavsiye dozunda K6'da en etkili olduğu ortaya çıkarılmıştır (Çizelge 1).

Kısır yabani yulaf bitki boylarında popülasyonların yarısının (K9, K6, M11, D6, D1, S5 ve S3) Mesosulfuron-methyl + Iodosulfuron-methyl sodium tavsiye dozunda istatistiki anlamda etkilendiği, kontrol olarak bırakılan bitkilerin boy uzunluğunun H5 hariç tüm popülasyonlarda en yüksek olduğu Çizelge 2'de görülmektedir. Popülasyonların \%20'sinin (H4, H2 ve S7) Mesosulfuron-methyl + Iodosulfuronmethyl sodium herbisitinin tavsiye dozu ile iki katı doz aralığında bitki boylarını etkilediği belirlenmiştir. Geri kalan popülasyonlardan T5 ile D3'ün tavsiye dozunun yarısından itibaren etkilendiği kaydedilmiştir. H5, K7 ve M3 popülasyonlarının ise kendi içerisinde sadece tavsiye dozunun iki katında etkilendiği saptanmıştır. Kontrolde bitki boylarındaki değişimlere bakıldığında H5 (11 cm) örnekleme noktası dışında diğer popülasyonların 21.10-33.00 cm arasında olduğu gözlenmiştir. Tavsiye dozunda etki belirlenen K9, K6, M11, D6, D1, S5 ve S3 popülasyonlarında bitki boylarının $6.40-16.70 \mathrm{~cm}$ arasında değiştiği, tavsiye dozu ile iki katı doz aralığında etki görülen popülasyonlara ait boyların ise 4.40-14.00 $\mathrm{cm}$ arasında olduğu görülmüştür (Çizelge 2). Benzer bir çalışmada Tardif ve Powles (1993) Avena sterilis, Lolium rigidum, L. multiflorum ve Sorghum halepense popülasyonlarına karşı ruhsatlı tavsiye dozunda kullanılan bazı herbisitlerin popülasyonlar üzerinde herhangi bir değişikliğe neden olmadığını bildirmiştir.

Clodinafop-propargyl herbisiti uygulaması sonrasinda ikinci sayım olan 28. gün sonunda popülasyonların kendi içerisinde bitki boyları kıyaslandığında popülasyonlarm \%27'sinin (H4, H2, D1, ve S3) tavsiye dozunda etki gördüğü, popülasyonların \%35'inin tavsiye dozu ile iki katı doz aralığında (T5, H5, K7, M3 ve S5) etkilendiği saptanmıştır. H2 popülasyonunun kontrol bitki boy uzunluğu $(15.50 \mathrm{~cm})$ çok düşük bulunmuştur. Kontroldeki bitki boyu değişim aralığının 21.00-34,60 $\mathrm{cm}$ arasında olduğu, tavsiye dozunda bitki boylarinin $\mathrm{H} 4, \mathrm{H} 2, \mathrm{D} 1$ ve $\mathrm{S} 3$ popülasyonlarında $7.50-14.90 \mathrm{~cm}$ arasında olduğu belirlenmiştir. Tavsiye dozu ile iki katı doz aralığında etki görülen popülasyonların bitki boylarındaki değişimlerde H5; 4.50 cm ile en düşük, S5; 20.60 ile en yüksek bulunmuş, diğer popülasyonlar bu boy uzunluğu aralığında değişkenlik göstermiştir (Çizelge 2). Adana'da yapılan bir çalışmada buğday ekim alanlarindan toplanan Phalaris brachystachys popülasyonlarının artık kullanılan ACCase ve ALS inhibitörü herbisitlerine karşı tavsiye dozunda bitki gelişiminde herhangi bir etkisinin olmadığ bildirilmiştir (Avcl, 2009). Clodinafop-propargyl tavsiye dozunun yarısında popülasyonların \%27'sinin (K9, M11, D6 ve S7) kendi içerisinde etkilendiği ve sadece iki katı uygulama dozunda ise $\mathrm{K} 6$ ve $\mathrm{D} 3$ popülasyonlarının etkilendiği saptanmıştır (Çizelge 2).

Kısır yabani yulafta bitki boylarına bakıldığında tavsiye dozunda D1 ve S3 popülasyonlarının iki herbisitte de etkilendiği belirlenmiştir. Tavsiye dozunda popülasyonun kendi içerisinde bitki boylarında etki görülen popülasyonların Mesosulfuron-methyl + Iodosulfuron-methyl sodium'da 7.60-16.70 cm, Clodinafop-propargyl'de $7.50-21.40 \mathrm{~cm}$ arasında olduğu saptanmıştır. Kısaca Mesosulfuron-methyl + Iodosulfuron-methyl sodium bitki boylarını Clodinafop-propargyl'e göre tavsiye dozda daha fazla etkilemiştir. Yine tavsiye dozu ile iki katı dozda etki görülen popülasyonların boy uzunluklarının Mesosulfuron-methyl + Iodosulfuronmethyl sodium'da daha etkili olduğu da kaydedilmiştir. Popülasyonlar arası istatistiki anlamda Mesosulfuron-methyl + Iodosulfuron-methyl sodium'un tavsiye dozunun yarısinda D3'de, tavsiye dozunda H2'de ve tavsiye dozunun iki katı uygulamasında $\mathrm{H} 5$ popülasyonunda en yüksek etkiyi gösterdiği görülmüştür. Clodinafop-propargyl'de popülasyonlar arasında istatistiki olarak en yüksek etkinin tavsiye dozunun yarısında H4, D3, S7 ve S5'de, tavsiye dozunda H5'de ve tavsiye dozunun iki katı uygulamasında gene D3 popülasyonunda olduğu Çizelde 2'de görülmektedir. Ayrıca tüm popülasyonlar arasında her iki herbisit de D3 popülasyonunda tavsiye dozunun yarısında en etkilidir. Amerika'da Ball ve ark. (2007) Bromus tectorum popülasyonlarında yaptıkları çalışmada yedi yıl üst üste herbisitle kimyasal mücadele yapılan tarlaları seçmiş ve bu popülasyonlarda muhtemel ACCase inhibitörü olan Fluazifop-p etkili maddesine karşı etkinliğin popülasyonlar üzerinde yıldan yıla azaldığını gözlemiştir. 
Çizelge 2. 2013 ve 2014 yıllarında Osmaniye ili örnekleme yapılan ilçelerde kısır yabani yulaf popülasyonlarıyla kurulan sera denemeleri sonucu Mesosulfuron-methyl + Iodosulfuron-methyl sodium (ALS) ve Clodinafop-propargyl (ACCase) herbisitlerinin bitki boyu $(\mathrm{cm})$ ortalamasina etkisi

Table 2. The effect of Mesosulfuron-methyl + Iodosulfuron-methyl sodium (ALS) and Clodinafop-propargyl (ACCase) herbicides on weed height $(\mathrm{cm})$ averages of screenhouse tests with wild oat populations in the sampling districts of Osmaniye province in 2013 and 2014

\begin{tabular}{|c|c|c|c|c|c|}
\hline \multirow{2}{*}{\multicolumn{2}{|c|}{$\begin{array}{l}\text { Bitki boyu }(\mathrm{cm}) \\
\text { Weed height }(\mathrm{cm})\end{array}$}} & \multicolumn{4}{|c|}{$\begin{array}{l}\text { Mesosulfuron-methyl + } \\
\text { Iodosulfuron-methyl sodium (ALS) }\end{array}$} \\
\hline & & \multirow{2}{*}{$\begin{array}{c}\begin{array}{c}\text { Kontrol } \\
\text { Control }\end{array} \\
6.70 \\
36.50 \\
\end{array}$} & \multirow{2}{*}{$\begin{array}{c}\mathrm{N} / 2 \\
10.00 \\
17.70 \\
\end{array}$} & \multirow{2}{*}{$\begin{array}{c}\text { N (Tavsiye dozu) } \\
\text { Recommended } \\
\text { dose } \\
8.50 \\
13.50\end{array}$} & \multirow{2}{*}{$\begin{array}{c}2 \mathrm{~N} \\
8.60 \\
18.00\end{array}$} \\
\hline \multirow{2}{*}{ Toprakkale 5(T5) } & $\begin{array}{l}\text { 1.Sayım } \\
\text { 2.Sayım }\end{array}$ & & & & \\
\hline & Fark & $29.80 \mathrm{c}$ & $\begin{array}{l}7.70 \mathrm{ab} \\
\mathrm{AB}\end{array}$ & $\begin{array}{l}5.00 \mathrm{a} \\
\mathrm{ABC}\end{array}$ & $\begin{array}{l}9.40 \mathrm{~b} \\
\mathrm{BCD}\end{array}$ \\
\hline \multirow{3}{*}{ Hasanbeyli 5(H5) } & 1.Sayım & 7.00 & 7.50 & 7.90 & 9.20 \\
\hline & 2.Sayım & 18.00 & 22.30 & 15.50 & 12.50 \\
\hline & Fark & $11.00 \mathrm{~b}$ & $\begin{array}{l}14.80 \mathrm{c} \\
\mathrm{C}\end{array}$ & $\begin{array}{c}7.60 \mathrm{~b} \\
\mathrm{ABCDE}\end{array}$ & $\begin{array}{c}3.30 \mathrm{a} \\
\mathrm{A}\end{array}$ \\
\hline \multirow{2}{*}{ Hasanbeyli 4(H4) } & $\begin{array}{l}\text { 1.Sayım } \\
\text { 2.Savım }\end{array}$ & $\begin{array}{c}7.90 \\
29.00\end{array}$ & $\begin{array}{c}7.80 \\
24.40\end{array}$ & $\begin{array}{c}7.30 \\
12.00\end{array}$ & $\begin{array}{c}6.90 \\
18.50\end{array}$ \\
\hline & Fark & $21.10 \mathrm{~d}$ & $\begin{array}{l}16.60 \mathrm{c} \\
\mathrm{CD}\end{array}$ & $\begin{array}{l}4.70 \mathrm{a} \\
\mathrm{AB}\end{array}$ & $\begin{array}{l}11.60 \mathrm{~b} \\
\mathrm{CDEF}\end{array}$ \\
\hline \multirow{3}{*}{ Hasanbeyli 2(H2) } & 1.Sayım & 8.50 & 9.30 & 8.10 & 7.50 \\
\hline & 2.Sayım & 32.50 & 19.80 & 12.50 & 15.00 \\
\hline & Fark & $24.00 \mathrm{c}$ & $\begin{array}{c}10.50 \mathrm{~b} \\
\mathrm{~B}\end{array}$ & $\begin{array}{c}4.40 \mathrm{a} \\
\mathrm{A}\end{array}$ & $\begin{array}{c}7.50 \mathrm{ab} \\
\mathrm{B}\end{array}$ \\
\hline \multirow{3}{*}{ Kadirli 9(K9) } & 1.Sayım & 7.40 & 8.30 & 8.10 & 9.30 \\
\hline & 2.Sayım & 36.00 & 33.60 & 18.50 & 21.60 \\
\hline & Fark & $28.60 \mathrm{~b}$ & $\begin{array}{l}25.30 \mathrm{~b} \\
\mathrm{E}\end{array}$ & $\begin{array}{l}10.40 \mathrm{a} \\
\mathrm{EF}\end{array}$ & $\begin{array}{l}12.30 \mathrm{a} \\
\mathrm{CDEF}\end{array}$ \\
\hline \multirow{3}{*}{ Kadirli 7(K7) } & 1.Sayım & 7.10 & 7.50 & 7.40 & 9.00 \\
\hline & 2.Sayım & 33.90 & 27.50 & 24.50 & 22.90 \\
\hline & Fark & $26.80 \mathrm{c}$ & $\begin{array}{l}20.00 \mathrm{~b} \\
\mathrm{D}\end{array}$ & $\begin{array}{l}\text { 17.10ab } \\
\mathrm{H}\end{array}$ & $\begin{array}{l}13.90 \mathrm{a} \\
\mathrm{F}\end{array}$ \\
\hline \multirow{3}{*}{ Kadirli 6(K6) } & 1.Sayım & $\begin{array}{c}8.30 \\
28.20\end{array}$ & 8.10 & 8.50 & 8.50 \\
\hline & 2.Sayım & 38.30 & 32.30 & 25.20 & 22.80 \\
\hline & Fark & $30.00 \mathrm{c}$ & $\begin{array}{c}24.20 \mathrm{~b} \\
\mathrm{E}\end{array}$ & $\begin{array}{c}16.70 \mathrm{a} \\
\mathrm{H}\end{array}$ & $\begin{array}{c}14.30 \mathrm{a} \\
\mathrm{F}\end{array}$ \\
\hline \multirow{3}{*}{ Merkez 11(M11) } & 1.Sayım & 8.20 & 7.90 & 9.30 & 8.40 \\
\hline & 2.Sayım & 33.20 & 26.00 & 22.30 & 19.60 \\
\hline & Fark & $25.00 \mathrm{c}$ & $\begin{array}{l}18.10 b \\
\text { CD }\end{array}$ & $\begin{array}{l}13.00 \mathrm{a} \\
\text { FG }\end{array}$ & $\begin{array}{l}11.20 \mathrm{a} \\
\text { BCDEF }\end{array}$ \\
\hline \multirow{3}{*}{ Merkez 3(M3) } & 1.Sayım & 8.30 & 8.30 & 8.80 & 6.50 \\
\hline & 2.Sayım & 38.50 & 28.30 & 23.00 & 16.50 \\
\hline & Fark & $30.20 \mathrm{~d}$ & $\begin{array}{l}20.00 \mathrm{c} \\
\mathrm{D}\end{array}$ & $\begin{array}{c}14.20 \mathrm{~b} \\
\mathrm{GH}\end{array}$ & $\begin{array}{l}10.00 \mathrm{a} \\
\mathrm{BCDE}\end{array}$ \\
\hline \multirow{3}{*}{ Düziçi 6(D6) } & 1.Sayım & 7.00 & 8.40 & 7.60 & 7.80 \\
\hline & 2.Sayım & 40.00 & 27.00 & 14.00 & 16.90 \\
\hline & Fark & $33.00 \mathrm{c}$ & $\begin{array}{l}18.60 \mathrm{~b} \\
\mathrm{D}\end{array}$ & $\begin{array}{r}6.40 \mathrm{a} \\
\mathrm{ABCD}\end{array}$ & $\begin{array}{l}9.10 \mathrm{a} \\
\mathrm{BC}\end{array}$ \\
\hline \multirow{3}{*}{ Düziçi 3(D3) } & 1.Sayım & 6.70 & 7.70 & 6.30 & 7.70 \\
\hline & 2.Sayım & 36.20 & 12.30 & 14.80 & 17.50 \\
\hline & Fark & $29.50 \mathrm{c}$ & $\begin{array}{c}4.60 \mathrm{a} \\
\mathrm{A}\end{array}$ & $\begin{array}{l}8.50 \mathrm{~b} \\
\mathrm{CDE}\end{array}$ & $\begin{array}{l}9.80 \mathrm{~b} \\
\mathrm{BCDE}\end{array}$ \\
\hline \multirow{3}{*}{ Düziçi 1(D1) } & 1.Sayım & 7.80 & 8.40 & 8.50 & 8.90 \\
\hline & 2.Sayım & 36.80 & 34.00 & 22.80 & 22.00 \\
\hline & Fark & $29.00 \mathrm{~b}$ & $\begin{array}{l}25.60 \mathrm{~b} \\
\mathrm{E}\end{array}$ & $\begin{array}{c}14.30 \mathrm{a} \\
\mathrm{GH}\end{array}$ & $\begin{array}{c}13.10 \mathrm{a} \\
\mathrm{DEF}\end{array}$ \\
\hline \multirow{3}{*}{ Sumbas $7(\mathrm{~S} 7)$} & 1.Sayım & 7.10 & 9.50 & 9.60 & 7.90 \\
\hline & 2.Sayım & 36.10 & 29.60 & 17.80 & 21.90 \\
\hline & Fark & $29.00 \mathrm{~d}$ & $20.10 c$ & $8.20 \mathrm{a}$ & $14.00 \mathrm{~b}$ \\
\hline
\end{tabular}

\begin{tabular}{|c|c|c|c|}
\hline \multicolumn{4}{|c|}{ Clodinafop-propargyl (ACCase) } \\
\hline $\begin{array}{l}\text { Kontrol } \\
\text { Control }\end{array}$ & $\mathrm{N} / 2$ & $\begin{array}{c}\text { N (Tavsiye dozu) } \\
\text { Recommended } \\
\text { dose }\end{array}$ & $2 \mathrm{~N}$ \\
\hline $\begin{array}{c}8.00 \\
37.00\end{array}$ & $\begin{array}{c}6.70 \\
29.50\end{array}$ & $\begin{array}{c}8.70 \\
21.50\end{array}$ & $\begin{array}{c}7.80 \\
25.30\end{array}$ \\
\hline $29.00 \mathrm{~d}$ & $\begin{array}{c}22.80 \mathrm{c} \\
\mathrm{CDE}\end{array}$ & $\begin{array}{c}12.80 \mathrm{a} \\
\mathrm{CD}\end{array}$ & $\begin{array}{c}17.50 \mathrm{~b} \\
\mathrm{EF}\end{array}$ \\
\hline $\begin{array}{c}9.10 \\
35.10\end{array}$ & $\begin{array}{c}7.70 \\
28.30\end{array}$ & $\begin{array}{c}7.50 \\
12.00\end{array}$ & $\begin{array}{c}8.10 \\
20.60\end{array}$ \\
\hline $26.00 \mathrm{~d}$ & $\begin{array}{l}20.60 c \\
\text { ABCD }\end{array}$ & $\begin{array}{c}4.50 \mathrm{a} \\
\mathrm{A}\end{array}$ & $\begin{array}{c}12.50 \mathrm{~b} \\
\mathrm{CD}\end{array}$ \\
\hline $\begin{array}{c}7.50 \\
32.50\end{array}$ & $\begin{array}{c}6.50 \\
24.50\end{array}$ & $\begin{array}{c}7.30 \\
14.80\end{array}$ & $\begin{array}{c}7.70 \\
16.20\end{array}$ \\
\hline $25.00 \mathrm{c}$ & $\begin{array}{c}18.00 \mathrm{~b} \\
\mathrm{~A}\end{array}$ & $\begin{array}{c}7.50 \mathrm{a} \\
\mathrm{AB}\end{array}$ & $\begin{array}{c}8.50 \mathrm{a} \\
\mathrm{AB}\end{array}$ \\
\hline $\begin{array}{c}8.50 \\
24.00\end{array}$ & $\begin{array}{c}7.50 \\
29.70 \\
\end{array}$ & $\begin{array}{c}7.80 \\
22.70\end{array}$ & $\begin{array}{c}7.80 \\
22.50\end{array}$ \\
\hline $15.50 \mathrm{a}$ & $\begin{array}{l}22.20 \mathrm{~b} \\
\mathrm{BCDE}\end{array}$ & $\begin{array}{c}14.90 \mathrm{a} \\
\mathrm{D}\end{array}$ & $\begin{array}{c}14.70 \mathrm{a} \\
\mathrm{DE}\end{array}$ \\
\hline $\begin{array}{c}8.60 \\
43.00\end{array}$ & $\begin{array}{c}8.40 \\
31.80\end{array}$ & $\begin{array}{c}8.30 \\
36.80\end{array}$ & $\begin{array}{c}8.30 \\
33.60\end{array}$ \\
\hline $34.40 \mathrm{c}$ & $\begin{array}{c}23.40 \mathrm{a} \\
\mathrm{DEF}\end{array}$ & $\begin{array}{c}28.50 \mathrm{~b} \\
\mathrm{~F}\end{array}$ & $\begin{array}{c}25.30 \mathrm{ab} \\
\mathrm{G}\end{array}$ \\
\hline $\begin{array}{c}8.80 \\
40.10\end{array}$ & $\begin{array}{c}6.50 \\
29.00\end{array}$ & $\begin{array}{c}6.70 \\
22.00\end{array}$ & \begin{tabular}{|c|}
7.20 \\
27.50 \\
\end{tabular} \\
\hline $31.30 \mathrm{c}$ & $\begin{array}{c}22.50 \mathrm{~b} \\
\mathrm{CDE}\end{array}$ & $\begin{array}{c}15.30 \mathrm{a} \\
\mathrm{D}\end{array}$ & $\begin{array}{c}20.30 b \\
F\end{array}$ \\
\hline $\begin{array}{c}7.00 \\
40.30\end{array}$ & $\begin{array}{c}7.50 \\
31.90\end{array}$ & $\begin{array}{c}8.30 \\
29.70\end{array}$ & $\begin{array}{c}6.80 \\
23.30\end{array}$ \\
\hline $33.30 \mathrm{c}$ & $\begin{array}{c}24.40 \mathrm{~b} \\
\mathrm{EF}\end{array}$ & $\begin{array}{c}21.40 \mathrm{~b} \\
\mathrm{E}\end{array}$ & $\begin{array}{c}16.50 \mathrm{a} \\
\mathrm{E}\end{array}$ \\
\hline $\begin{array}{c}8.00 \\
37.50\end{array}$ & $\begin{array}{c}9.30 \\
29.30\end{array}$ & $\begin{array}{c}8.30 \\
33.90\end{array}$ & $\begin{array}{c}8.00 \\
38.50\end{array}$ \\
\hline $29.50 \mathrm{c}$ & $\begin{array}{l}20.00 \mathrm{a} \\
\mathrm{ABCD}\end{array}$ & $\begin{array}{c}25.60 \mathrm{~b} \\
\mathrm{~F}\end{array}$ & $\begin{array}{c}30.50 \mathrm{c} \\
\mathrm{H}\end{array}$ \\
\hline $\begin{array}{c}7.40 \\
35.50\end{array}$ & $\begin{array}{c}6.80 \\
33.50\end{array}$ & $\begin{array}{c}6.00 \\
15.80\end{array}$ & $\begin{array}{c}7.30 \\
22.30\end{array}$ \\
\hline $28.10 \mathrm{c}$ & $\begin{array}{l}26.70 \mathrm{c} \\
\mathrm{F}\end{array}$ & $\begin{array}{c}9.80 \mathrm{a} \\
\mathrm{BC}\end{array}$ & $\begin{array}{c}15.00 \mathrm{~b} \\
\mathrm{DE}\end{array}$ \\
\hline $\begin{array}{c}9.40 \\
30.40\end{array}$ & $\begin{array}{c}7.00 \\
25.60\end{array}$ & $\begin{array}{c}7.80 \\
20.60\end{array}$ & $\begin{array}{c}7.20 \\
32.20\end{array}$ \\
\hline $21.00 \mathrm{~b}$ & $\begin{array}{c}18.60 \mathrm{~b} \\
\mathrm{AB}\end{array}$ & $\begin{array}{c}12.80 \mathrm{a} \\
\mathrm{CD}\end{array}$ & $\begin{array}{c}25.00 \mathrm{c} \\
\mathrm{G}\end{array}$ \\
\hline $\begin{array}{c}8.50 \\
36.00\end{array}$ & $\begin{array}{c}7.40 \\
24.50\end{array}$ & $\begin{array}{c}9.50 \\
23.80\end{array}$ & $\begin{array}{c}9.30 \\
15.00\end{array}$ \\
\hline $27.50 \mathrm{c}$ & $\begin{array}{c}17.10 \mathrm{~b} \\
\mathrm{~A}\end{array}$ & $\begin{array}{c}14.30 \mathrm{~b} \\
\mathrm{D}\end{array}$ & $\begin{array}{c}5.70 \mathrm{a} \\
\mathrm{A}\end{array}$ \\
\hline $\begin{array}{c}7.80 \\
42.40\end{array}$ & $\begin{array}{c}7.40 \\
30.90\end{array}$ & $\begin{array}{c}8.80 \\
20.90\end{array}$ & $\begin{array}{c}8.20 \\
22.70\end{array}$ \\
\hline $34.60 \mathrm{c}$ & $\begin{array}{c}23.50 \mathrm{~b} \\
\mathrm{DEF}\end{array}$ & $\begin{array}{c}12.10 \mathrm{a} \\
\mathrm{CD}\end{array}$ & $\begin{array}{c}14.50 \mathrm{a} \\
\mathrm{CDE}\end{array}$ \\
\hline $\begin{array}{c}8.70 \\
37.70\end{array}$ & $\begin{array}{c}9.50 \\
27.80\end{array}$ & $\begin{array}{c}9.00 \\
34.60\end{array}$ & $\begin{array}{c}7.30 \\
31.40\end{array}$ \\
\hline $29.00 \mathrm{c}$ & $18.30 \mathrm{a}$ & $25.60 \mathrm{bc}$ & $24.10 \mathrm{~b}$ \\
\hline
\end{tabular}




\begin{tabular}{|c|c|c|c|c|c|c|c|c|c|}
\hline & & & $\mathrm{D}$ & BCDE & $\mathrm{F}$ & & $\mathrm{A}$ & $\mathrm{F}$ & $\mathrm{G}$ \\
\hline \multirow[b]{2}{*}{ Sumbas 5(S5) } & $\begin{array}{l}\text { 1.Sayım } \\
\text { 2.Sayım }\end{array}$ & $\begin{array}{c}7.60 \\
33.00\end{array}$ & $\begin{array}{c}9.20 \\
28.80\end{array}$ & $\begin{array}{c}9.50 \\
20.80\end{array}$ & $\begin{array}{c}7.60 \\
20.90\end{array}$ & $\begin{array}{c}8.40 \\
34.40\end{array}$ & $\begin{array}{c}8.10 \\
26.10\end{array}$ & $\begin{array}{c}6.50 \\
19.60\end{array}$ & $\begin{array}{c}6.80 \\
27.40\end{array}$ \\
\hline & Fark & $25.40 \mathrm{c}$ & $\begin{array}{c}19.60 \mathrm{~b} \\
\mathrm{D}\end{array}$ & $\begin{array}{c}11.30 \mathrm{a} \\
\mathrm{EFG}\end{array}$ & $\begin{array}{c}13.30 \mathrm{a} \\
\mathrm{EF}\end{array}$ & $26.00 \mathrm{c}$ & $\begin{array}{c}18.00 \mathrm{~b} \\
\mathrm{~A}\end{array}$ & $\begin{array}{c}13.10 \mathrm{a} \\
\text { CD }\end{array}$ & $\begin{array}{c}20.60 \mathrm{~b} \\
\mathrm{~F}\end{array}$ \\
\hline \multirow{2}{*}{ Sumbas $3(\mathrm{~S} 3)$} & $\begin{array}{l}\text { 1.Sayım } \\
\text { 2.Sayım }\end{array}$ & $\begin{array}{c}7.40 \\
32.00 \\
\end{array}$ & $\begin{array}{c}7.90 \\
26.00 \\
\end{array}$ & $\begin{array}{c}7.50 \\
17.10 \\
\end{array}$ & $\begin{array}{c}8.30 \\
19.90 \\
\end{array}$ & $\begin{array}{c}7.00 \\
34.70 \\
\end{array}$ & $\begin{array}{c}8.40 \\
28.00 \\
\end{array}$ & $\begin{array}{c}7.10 \\
17.10 \\
\end{array}$ & $\begin{array}{c}7.80 \\
18.80 \\
\end{array}$ \\
\hline & Fark & $24.60 \mathrm{c}$ & $\begin{array}{c}18.10 \mathrm{~b} \\
\mathrm{CD}\end{array}$ & $\begin{array}{l}9.60 \mathrm{a} \\
\mathrm{DEF}\end{array}$ & $\begin{array}{l}11.60 a \\
\text { CDEF }\end{array}$ & $27.70 \mathrm{c}$ & $\begin{array}{c}19.60 \mathrm{~b} \\
\mathrm{ABC}\end{array}$ & $\begin{array}{c}10.00 \mathrm{a} \\
\mathrm{BC}\end{array}$ & $\begin{array}{c}11.00 \mathrm{a} \\
\mathrm{BC}\end{array}$ \\
\hline
\end{tabular}

*Aynı satırda farklı küçük harflerle ve aynı sütunda farklı büyük harflerle gösterilen ortalamalar Duncan Çoklu Karşılaştırma Testine göre $\mathrm{P}<0.05$ önem seviyesinde birbirinden farklıdır.

Çizelge 3. 2013 ve 2014 yıllarında Osmaniye ili örnekleme yapılan ilçelerde kısır yabani yulaf popülasyonlarıyla kurulan sera denemeleri sonucu popülasyon içerisinde kontrole göre Mesosulfuron-methyl + Iodosulfuron-methyl sodium (ALS) ve Clodinafop-propargyl (ACCase) tavsiye dozunun yaş ağırlık ve bitki boyu ortalamalarına karşı yüzde (\%) etkisi

Table 3. The effect of Mesosulfuron-methyl + Iodosulfuron-methyl sodium (ALS) and Clodinafop-propargyl (ACCase) recommended doses compared to the weed biomass and weed height averages (\%) according to the control of screenhouse tests with wild oat populations in the sampling districts of Osmaniye province in 2013 and 2014

\begin{tabular}{|c|c|c|c|c|}
\hline \multirow{2}{*}{$\begin{array}{c}\text { Popülasyon } \\
\text { Population }\end{array}$} & \multicolumn{2}{|c|}{ Yaş ağırlik \% etki } & \multicolumn{2}{c|}{$\begin{array}{c}\text { Bitki boyu \% etki } \\
\text { Weed height \% effect }\end{array}$} \\
\cline { 2 - 5 } & $\begin{array}{c}\text { Mesosulfuron-methyl } \\
\text { + Iodosulfuron-methyl } \\
\text { sodium (ALS) }\end{array}$ & $\begin{array}{c}\text { Clodinafop-propargyl } \\
\text { (ACCase) }\end{array}$ & $\begin{array}{c}\text { Mesosulfuron-methyl } \\
\text { + Iodosulfuron-methyl } \\
\text { sodium (ALS) }\end{array}$ & $\begin{array}{c}\text { Clodinafop- } \\
\text { propargyl } \\
\text { (ACCase) }\end{array}$ \\
\hline Toprakkale 5(T5) & 77.06 & 36.29 & 83.22 & 55.86 \\
\hline Hasanbeyli 5(H5) & 75.35 & 3.12 & 30.91 & 82.69 \\
\hline Hasanbeyli 4(H4) & 52.30 & 25.00 & 77.73 & 70.00 \\
\hline Hasanbeyli 2(H2) & 64.44 & 49.39 & 81.67 & 3.87 \\
\hline Kadirli 9(K9) & 37.62 & 51.33 & 63.64 & 17.15 \\
\hline Kadirli 7(K7) & 65.07 & 17.28 & 36.19 & 51.12 \\
\hline Kadirli 6(K6) & 71.95 & 42.42 & 44.33 & 35.74 \\
\hline Merkez 11(M11) & 61.72 & 29.31 & 48.00 & 13.22 \\
\hline Merkez 3(M3) & 62.72 & 46.75 & 52.98 & 65.12 \\
\hline Düziçi 6(D6) & 43.75 & 42.85 & 80.61 & 39.05 \\
\hline Düziçi 3(D3) & 42.45 & 24.81 & 71.19 & 48.00 \\
\hline Düziçi 1(D1) & 52.71 & 39.85 & 50.69 & 65.03 \\
\hline Sumbas 7(S7) & 70.90 & 39.86 & 71.72 & 11.72 \\
\hline Sumbas 5(S5) & 42.85 & 15.78 & 55.51 & 49.62 \\
\hline Sumbas 3(S3) & 39.13 & 15.89 & 60.98 & 63.90 \\
\hline
\end{tabular}

*Serada yapılan çalışmada \%60 ve üstü önemli olarak kaydedilmiştir.

Tavsiye dozunda kullanılan Mesosulfuron-methyl + Iodosulfuron-methyl sodium ve Clodinafop-propargyl herbisitlerinin bitki boyları ve yaş ağırlıkları üzerindeki yüzde etkiler yapılan çalışmayla belirlenmiştir. Yaş ağırlıklarda tavsiye dozda Mesosulfuron-methyl + Iodosulfuron-methyl sodium'a etki bulunan popülasyonlar T5, H4, H2, K6, M11, D1 ve S5 popülasyonları olup, bu popülasyonlardan T5; \%77.06 en yüksek, S5; \%42.85 en düşük yüzde etkiye sahip olmuştur. Clodinafop-propargyl'de ise her ne kadar istatistiki anlamda T5, H2 ve D6 popülasyonlarının tavsiye dozunda etki görülse de bu popülasyonların yaş ağırlığına yüzde etkisi \%50'nin altında kalmıştır. H2 popülasyonu \%49.39 ile en yakın bulunmuştur (Çizelge 3). Fahad ve ark. (2013) yaptıkları çalışmada buğdayda farklı herbisitleri seçerek Convolvulus arvensis, Avena fatua, Phalaris minor, Galium aparine, Fumaria indica ve Melilotus indica türlerinin bulunduğu alanlarda deneme kurmuş ve \%87 ile Isoproturon etkili maddeli herbisitin en fazla yabancı ot yaş ağırlığını etkilendiğini bildirmiştir. Avrupa Hırvatistan'da buğdayda Iodosulfuron-methyl sodium + Mefenpyrdiethyl, Fluoroglycofene-ethyl + Triasulfuron ve 2.4-D ester + Metosulam herbisitlerinin karışımını düşük dozda geniş yapraklı yabancı otlardan Matricaria inodora, Ambrosia artemisiifolia, Galium aparine ve Stellaria media türlerinin hakim olduğu deneme alanında uygulayarak yaş ağırlıkların \%89-100 arasında değiştiğini belirlemiştir (Knezevic ve ark., 2008). Litvanya'da ise Florasulam + 2.4-D ester herbisitinin 4 farklı uygulama dozu kullanılmış ve 
Stellaria media, Chenopodium album, Galeopsis tetrahit ile Sinapis arvensis türlerinin farklı gelişim dönemlerine ait yaş ağırlıklar üzerindeki etkiler araştırılarak en etkin belirlenen dozda \%75-95 arasında etki ortaya çıkarılmıştır (Auskalnis ve Kadzys, 2006). Böylelikle yabancı ot türlerine ve herbisitlerin özelliklerine göre yaş ağırlıklar üzerinde herbisit etkilerinin değişebileceği saptanmıştır.

Bitki boyları açısından Mesosulfuron-methyl + Iodosulfuron-methyl sodium tavsiye dozunda istatistiki anlamda etki saptanan K9, K6, M11, D6, D1, S5 ve S3 popülasyonlarından sadece D6 popülasyonunun yüksek etki gösterdiği belirlenmiştir (Çizelge 3). Benzer bir çalışmada Bibi ve ark. (2008) Pakistan'da buğdayda yabancı otlara karşı bazı herbisitlerin uygulama sonrası bitki boyları üzerindeki etkilerini araştırmış, hasat öncesi kontrolde en fazla bitki boyu olduğunu, diğer bitki boylarının yakın ancak Clodinafop-propargyl ve Carfentrazon ethyl-ester herbisitlerinde bitki boylarının daha kısa olduğunu belirlemiştir. Çukurova'da yapılan çalışmalarda da kısır yabani yulafa karşı ALS ve ACCase inhibitörü herbisitlerin farklı uygulama dozlarında bitki boylarını etkilediği ortaya konmuştur (Yücel, 2004; Avcı, 2009; Ayata, 2014; Gürbüz, 2016; Torun, 2017). Yapılan çalışmalarla herbisitler tarafından bitki boylarının etkilenebileceği ve farklı uygulama dozlarının ortam koşullarına göre popülasyonlarda farklılık oluşturabileceği ortaya çıkarılmıştır. Bu çalışmada ise popülasyonlar üzerinde tavsiye dozunda bitki boylarına karşı ACCase inhibitörü herbisitinin etkisinin, ALS inhibitörü herbisitine göre daha az olduğu sera çalışmalarında belirlenmiştir. Uygulanan ACCase herbisitinde H4, H2, D1 ve S3 popülasyonları tavsiye dozunda etkili bulunmuştur fakat sadece $\mathrm{H} 4$, D1 ve S3 popülasyonlarında \%63.00-70.00 arasında değişen bir etki görülmüştür (Çizelge 3). Kanada'da Legere ve ark. (2000) Avena fatua popülasyonlarında kullanılan herbisitlerin etkinliğinin arttırılması adına farklı etki mekanizmasina sahip herbisitlerin kesinlikle kullanılmasının önemini belirtmiştir. Hububat ve geniş yaprakl ürünlerde herbisit rotasyonunun yapılarak yabancı otlar üzerinde herbisit etkinliğinin sadece bu yolla sağlanabileceğini bildirmiştir.

\section{SONUÇ}

Kısaca yapılan çalışmada buğdayda kullanılan ALS ve ACCase inhibitörlerinin popülasyonlar üzerindeki değişimleri belirlenmiş ve sera çalışmalarında gerek bitki boyuna, gerekse yaş ağırlığa olan etkilerinin ALS inhibitörü tavsiye dozunda daha fazla olduğu saptanmıştır. Ayrıca ACCase inhibitöründe popülasyonlarda en fazla bitki boyu ve yaş ağırlığa etki eden doz aralığının tavsiye dozu ile iki katı doz aralığ olduğu belirlenmiştir. Özellikle buğdayda sorun olan yabancı otlarla kimyasal mücadelede kesinlikle farklı etki mekanizmasına sahip herbisitler tercih edilmelidir. Çünkü aynı etki mekanizmasının tarlalarda daimi kullanımı sorun olan yabancı ot türleri üzerinde herbisit etkinliğinin yitirilmesine sebep olabilmektedir. Buğdayda farklı etki mekanizmasina sahip herbisitlerin kullanımıyla tarlalar herbisit rotasyonuna tabii tutulmalı ve sorun olan yabancı otlarla mücadelede herbisit etiketi üzerinde yazan tavsiye dozunda uygulanmalıdır. Ancak temel anlamda kimyasal mücadelede herbisitlerin uygulanmasında yabancı otlara karşı olan etkiyi arttırmak istiyorsak muhakkak üretici nezdinde hatalı ve yanlış uygulamalardan dolayı bilinçlendirme yapılmalı ve farklı ürün rotasyonları da tarlalarda uygulanmalıdır.

\section{Çıkar Çatışması Beyanı}

Makale yazarları aralarında herhangi bir çıkar çatışması olmadığını beyan ederler.

\section{Araştırmacıların Katkı Oranı Beyan Özeti}

Yazarlar makaleye eşit oranda katkı sağlamış olduklarını beyan ederler.

\section{KAYNAKLAR}

Abbott WS 1925. A Method of Computing the Effectiveness of an Insecticide. Journal of Economic Entomology, 18(2): 265-267.

Anonim 2009. PASW Statistics for Windows, Version 18.0. Chicago: SPSS Inc. Retrieved Janurary 13, 2013.

Auskalnis A, Kadzys A 2006. Effect of Timing and Dosage in Herbicide Application on Weed Biomass in Spring Wheat. Agronomy Research, 4(Special Issue): $133-136$.

Avcı ÇM 2009. Çukurova Bölgesi Buğday Ekim Alanlarmda Sorun Olan Phalaris brachystachys Link. (Kanlı Çayır)'in Bazı Buğday Herbisitlerine Karşı Oluşturduğu Dayanıklılık Sorunlarının Araştırılması. Çukurova Üniversitesi Fen Bil. Ens., Bitki Koruma ABD, Yüksek Lisan Tezi, 63 s.

Ayata MU 2014. Adana İli Buğday Ekim Alanlarında Kısır Yabani Yulaf (Avena sterilis L.)'in ACCase (Acetyl-Coa Carboxylase) Enzimi İnhibitörü Herbisitlere Karşı Oluşturduğu Dayanıklılığın Önemi ve Dayanıklı Popülasyonların Haritasının Oluşturulması. Çukurova Üniversitesi Fen Bil. Ens., Bitki Koruma ABD, Yüksek Lisans Tezi, 157 s.

Ball DA, Frost SM, Bennett LH 2007. ACCaseinhibitor Herbicide Resistance in Downy Brome (Bromus tectorum) in Oregon. Weed Science, 55: 91-94.

Beckie HJ, Kirkland KJ 2003. Implication of Reduced Herbicide Rates on Resistance Enrichment in Wild Oat (Avena fatua). Weed Technology, 17: 138-148. 
Bibi S, Marwat KB, Hassan G, Khan NM 2008. Effect of Herbicides and Wheat Population on Control of Weeds in Wheat. Pakistan Journal of Weed Science Research, 14(3-4): 111-119.

Carlson HL, Hill JE 1985. Wild Oat (Avena fatua) Competition with Spring Wheat: Effects of Nitrogen Fertilization. Weed Science, 34(1): 29-33.

Fahad S, Nie L, Rahman A, Chen C, Wu C, Saud S, Huang J 2013. Comparative Efficacy of Different Herbicides for Weed Management and Yield Attributes in Wheat. American Journal of Plant Sciences, 4(6):1241-1245.

Gürbüz R 2016. Adana Illi Buğday Ekim Alanlarında ALS İnhibitörü Herbisitlere Karşı Dayanıklılık Kazanmış Yabani Yulaf (Avena sterilis L.) ile Yabani Hardal (Sinapis arvensis L.) Popülasyonlarının Belirlenmesi ve Dayanıklılık Haritalarının Oluşturulması. Çukurova Üniversitesi Fen Bil. Ens., Bitki Koruma ABD, Doktora Tezi, $321 \mathrm{~s}$.

Heap IM, Knight R 1986. The Occurrence of Herbicide Cross Resistance in A Population of Annual Ryegrass, Lolium rigidum, Resistant to DiclofopMethyl. Australian Journal of Agricultural Research, 37: 149-156.

Heap IM, Murray BG, Loeppky HA, Morrison IN 1993. Resistance to Aryloxyphenoxypropionate and Cyclohexanedione Herbicides in Wild Oat (Avena fatua). Weed Science, 41(2): 232-238.

Kadıŏglu İ, Uluğ E, Uygur FN, Üremiş İ, Boz Ö 1993. Çukurova Buğday Ekim Alanlarında Görülen Yabani Yulaf (Avena sterilis L.)'ın Ekonomik Zarar Eşiği Üzerinde Araştırmalar. Türkiye I.Herboloji Kongresi, 03-05 Şubat, Adana, Türkiye.

Kadıoğlu İ, Uygur FN, Çınar A 1990. Yabani Yulaf (Avena sterilis L.)'ın Yok Edilme Zamanının Buğday Gelişimi ve Verimine Etkisi. Çukurova Üniversitesi Ziraat Fakültesi Dergisi, 5(4): 71-76.

Knezevic M, Ranogajec L, Samota D 2008. The Effect of Plant Density on Forage and Seed Yields and Quality of Red Clover (Trifolium pratense L.). Proceedings of the VII. Alps-Adria Scientific Workshop, Cereal Research Communications, 28 April-02 May, Stara Lesna, Slovakia.
Legere A, Beckie HJ, Stevenson FC, Thomas AG 2000. Survey of Management Practices Affecting the Occurrence of Wild Oat (Avena fatua) Resistance to Acetyl-Coa Carboxylase Inhibitors. Weed Technology, 14(2): 366-376.

Mansooji AM, Holtum JA, Boutsalis P, Matthews JM, Powles SB 1992. Resistance to Aryloxyphenoxypropionate Herbicides in Two Wild Oat Species (Avena fatua and Avena sterilis ssp. ludoviciana). Weed Science, 40(4): 599-605.

Preston C, Powles SB 2002. Evolution of Herbicide Resistance in Weeds: Initial Frequency of Target Site-based Resistance to Acetolactate Synthaseinhibiting Herbicides in Lolium rigidum. Heredity, 88: 8-13.

Seefeldt SS, Gealy DR, Brewster BD, Fuerst EP 1994. Cross-resistance of Several Diclofop-resistant Wild Oat (Avena fatua) Biotypes from the Willamette Valley of Oregon. Weed Science, 42(3): 430-437.

Tardif FJ, Powles SB 1993. Target Site-based Resistance to Herbicides Inhibiting Acetyl-CoA Carboxylase. Brighton Crop Protection Conference, Weeds, 22-25 November, Brighton, UK.

Torner C, Gonzalez-Andujar JL, FernandezQuintanilla C 1991. Wild Oat (Avena sterilis L.) Competition with Winter Barley: Plant Density Effects. Weed Research, 31(5): 301-307.

Torun H 2017. Osmaniye İli’nde Ekim Nöbetinin Kısır Yabani Yulafta (Avena sterilis L.) Oluşmuş Herbisit Direncine Etkisinin Araştırılması ve Haritalaması. Çukurova Üniversitesi Fen Bil. Ens., Bitki Koruma ABD, Doktora Tezi, $225 \mathrm{~s}$.

Uygur FN, Koch W, Walter H 1984. Yabancl Ot Bilimine Giriş, PLITS 1984/2(1), Verlog J. Margraf, Stuttgart, $114 \mathrm{~s}$.

Valverde BE (2007) Status and Management of Grassweed Herbicide Resistance in Latin America. Weed Technology, 21(2): 310-323.

Yücel E 2004. Çukurova Bölgesi Buğday Ekim Alanlarında Sorun Olan Kısır Yabani Yulaf (Avena sterilis L.)'ın Bazı Herbisitlere Karşı Ortaya Çıkan Dayanıklılık Sorunlarının Araştırılması. Çukurova Üniversitesi Fen Bil. Ens., Bitki Koruma ABD, Yüksek Lisans Tezi, $96 \mathrm{~s}$. 